\title{
O modelo de cooperação do tribunal penal internacional
}

\author{
João Irineu de Resende Miranda ${ }^{1}$
}

\section{Resumo}

Este artigo estuda o modelo de cooperação do Estatuto de Roma para buscar determinar a razão pela qual o Tribunal Penal Internacional tem enfrentado problemas nessa área. Acredita-se que uma análise sistemática do tema à luz da Teoria da Responsabilidade Internacional do Estado por Atos Ilícitos pode contribuir significativamente para o trato da questão. Para isso, o artigo realiza uma análise dos artigos do Capítulo IX do documento para, por meio do método dedutivo, evidenciar suas lacunas e contradições. Conclui-se que o atual modelo de cooperação presente no Estatuto de Roma não permite que o Tribunal Penal Internacional cumpra fielmente suas funções porque preserva prerrogativas estatais em demasia e não prevê sanções específicas para o não cumprimento dos pedidos de cooperação endereçados aos Estados.

Palavras-chave: Tribunal Penal Internacional. Estatuto de Roma. Cooperação internacional.

\section{Introdução}

O Tribunal Penal Internacional entrou em funcionamento em julho de 2002 com a missão de julgar os indivíduos acusados dos mais graves crimes no entendimento da comunidade internacional. ${ }^{2}$ Concebido à semelhança dos tribunais

1 Professor Adjunto do Departamento de Direito das Relações Sociais da Universidade Estadual de Ponta Grossa. Doutor em Direito Internacional pela Faculdade de Direito da Universidade de São Paulo.

2 BRASIL.Decreto $n^{\circ} 4388 / 2002$ (Estatuto de Roma). Disponível em www.planalto.gov.br Acesso em 20/04/2010. Artigo 1 ${ }^{\circ}$. O Tribunal. É criado pelo presente instrumento, um Tribunal Penal Internacional ("o Tribunal"). O Tribunal será uma instituição permanente, com jurisdição sobre as pessoas responsáveis pelos crimes de maior gravidade com alcance internacional, de acordo com o presente Estatuto, e será complementar às jurisdições penais nacionais. A competência e o funcionamento do Tribunal regular-se-ão pelo presente Estatuto. 
criados pelo Conselho de Segurança da ONU, sua jurisdição complementar e seu caráter permanente tornaram-no um marco para os Direitos Humanos e para o Direito Internacional. Além disso, suas implicações para a Ordem Internacional são profundas, pois sua jurisdição foi concebida de forma a alcançar potencialmente qualquer indivíduo que tenha cometido crimes de sua competência. Não é de se estranhar, dessa forma, que o Tribunal Penal Internacional tenha enfrentado a oposição de importantes Estados dentro da Ordem Internacional.

Às vésperas de sua primeira Conferência de Revisão, contudo, o Tribunal enfrenta dificuldades em cumprir seu papel. Como não possui polícia judiciária, o Tribunal precisa da ajuda dos Estados para acolher e preservar provas, obter depoimentos de funcionários públicos, proteger testemunhas e cumprir mandados de prisão, além de outros procedimentos. Os Estados destinatários de requerimentos de cooperação, muitas vezes, apresentam obstáculos para seu cumprimento ou simplesmente os ignoram. Muito embora a responsabilidade por crimes internacionais seja individual, para que possa existir efetivo julgamento e punição aos responsáveis, é indispensável o concurso, ou, pelo menos, a não obstrução desses Estados.

A recente história das instituições penais internacionais demonstra que a falta de cooperação ou mesmo a sabotagem de indivíduos que se encontram na posição de órgãos de Estado tem sido um importante obstáculo para o sucesso dos tribunais. ${ }^{3}$ Tal situação também pode ser percebida quando se analisam os casos em andamento ou sob investigação do Tribunal Penal Internacional. Na República Democrática do Congo, a prisão e entrega dos acusados depende de sua posição política perante o governo central e não da magnitude de seus crimes. ${ }^{4}$ Em Uganda, o pedido de investigação e o consequente indiciamento de líderes rebeldes foram subvertidos pelo governo de Kampala em matéria de barganha de um confuso processo de paz que até o momento não foi capaz de encerrar a longa guerra civil

3 PENROSE, Mary Elizabeth. Lest we fail [...].the importance of enforcement in international criminal law. American University International Law Review, Washington D.C. v. 15, n. 2, p. 321-94, 1999.

4 AKHAVAN, Payam. Are International Criminal Tribunals a disincentive to peace?: Reconciling judicial romantism with political realism. Human Rights Quarterly, Cincinnat, n. 31, p. 624-654, 2009. 
naquele país. ${ }^{5}$ No Sudão, o indiciamento do Presidente Bashir revelou a debilidade do mandado de prisão internacional expedido pelo Tribunal. Alguns Estados Parte parecem cooperar silenciosamente a favor da impunidade do líder sudanês, avisando-o da existência de um pedido de cooperação em sua prisão feito pelo Tribunal ou detendo-se em questionamentos jurídicos a respeito de sua obrigação de cooperar. Outros Estados chegam mesmo a contrapor-se ao Tribunal, endossando as posturas hostis da Liga Árabe e da União Africana. ${ }^{6}$

Em vista disso, o modelo de cooperação com os Estados e organizações internacionais previsto pelo Estatuto de Roma é um dos assuntos constantes da pauta de discussão de sua primeira Conferência de Revisão deste documento, a ser realizada entre os dias 31 de maio e 10 de junho de $2010 .^{7}$

Este artigo analisa as disposições do Capítulo IX do Estatuto de Roma de forma a tentar demonstrar porque suas disposições, embora formalmente implementadas com a entrada vigor do Estatuto em 2002, parecem carecer de efetividade. Utilizando-se do método dedutivo para analisar os artigos que regulamentam a obrigação dos Estados de cooperarem com o Tribunal à luz da Teoria da Responsabilidade Internacional do Estado por Atos Ilícitos, propõe-se que a não efetividade do Tribunal está relacionada à falta de previsão, no Estatuto de Roma, de sanções específicas para o descumprimento pelos Estados de pedidos de cooperação enviados pelo Tribunal.

Desse modo, este artigo inicia-se com uma sintética apresentação acerca do Estatuto de Roma para, em seguida, aprofundar-se na análise dos artigos de seu Capítulo IX, referentes à cooperação internacional, seguindo-se de uma breve remissão aos conceitos afetos à Teoria da Responsabilidade Internacional do Estado por Atos Ilícitos concernentes ao objetivo proposto.

5 PESKIN, Victor. Caution and confrontation in the International Criminal Court's pursuit of accountability in Uganda and Sudan. Human Rights Quarterly, Cincinnati, v. 31, n. 3, p. 655-691, Aug. 2009.

6 PESKIN, Victor. Caution and confrontation in the International Criminal Court's pursuit of accountability in Uganda and Sudan. Human Rights Quarterly, Cincinnati, v. 31, n. 3, p. 655-691, Aug. 2009.

7 INTERNATIONAL CRIMINAL COURT. Assembly of the States Parties. Report of the bureau of stocktaking: cooperation, New York, p. 22-25, Mar. 2010. Session 8. 


\section{0 estatuto de Roma do tribunal penal internacional}

O Estatuto de Roma é o tratado multilateral que criou o primeiro Tribunal Penal Internacional de caráter permanente da História. Foi adotado em 17 de julho de 1998 , tendo entrado em vigor em $1^{\circ}$ de julho de 2002 . Foi promulgado no Brasil através do Decreto no 4.388 de 25 de setembro de 2002. Possui 139 assinaturas, tendo sido ratificado por 111 Estados. ${ }^{8}$ Divide-se em treze capítulos e 128 artigos, não admitindo reservas, podendo ser ratificado somente em sua integralidade nos termos do seu artigo 120. A única exceção a essa regra é a disposição transitória do artigo 124, que permite ao Estado Parte afastar a competência do Tribunal Penal Internacional sobre crimes de guerra, disposta no artigo $8^{\circ}$, por sete anos após o Estatuto entrar em vigor, desde que tenha formulado um pedido nesses termos no momento da ratificação. Também em sete anos após sua entrada em vigor, está prevista uma Conferência de Revisão do Estatuto de Roma, no artigo 123, podendo os Estados Parte do Tribunal Penal Internacional, proporem, a qualquer momento após essa data, alterações ao Estatuto de Roma, nos termos de seu artigo 121.

O Preâmbulo do Estatuto de Roma, como o dos demais tratados internacionais, consiste em uma importante parte do documento, tendo em vista que fornece os princípios e os valores fundamentais a serem considerados na interpretação de suas normas. Inicia por afirmar o caráter universal dos direitos humanos enquanto laços e heranças comuns a todos os povos e, com base nessa afirmação, afirma que existem crimes tão graves que constituem uma ameaça aos valores comuns de toda a humanidade tais como paz, segurança e bem-estar. Em vista disso, constata que esses crimes constituem uma ameaça à humanidade como um todo, salientando que não devem permanecer impunes. Conclama, então, suas Partes, à adoção de medidas em âmbito nacional e recorda que é dever de cada Estado exercer a respectiva jurisdição penal. Assevera, contudo, que esses crimes, por afetarem a humanidade em seu conjunto, possuem natureza internacional, e sua repressão deve ser reforçada por medidas de cooperação internacional. Para que essa cooperação tenha êxito e a justiça internacional seja efetivada, o Preâmbulo aponta a determinação de os Estados que assinam e ratificam o Estatuto de Roma criarem

${ }^{8}$ INTERNATIONAL CRIMINAL COURT. Office of the Registrar. Ratification Status. Disponível em: <www.icc-cpi.int>. Acesso em: 30 abr. 2010. 
o Tribunal Penal Internacional, cuja jurisdição será complementar às jurisdições penais nacionais. Assim, enquanto jurisdição complementar, o Preâmbulo adverte que nenhuma disposição do Estatuto de Roma deve ser interpretada de forma a autorizar que um Estado Parte realize uma intervenção em outro Estado em desacordo com os objetivos e princípios consignados na Carta das Nações Unidas.

A jurisdição internacional regulamentada pelo Estatuto de Roma não se caracteriza como uma ordem hierarquizada em relação às jurisdições penais de seus Estados Partes, mas como uma ordem interativa, baseada na complementaridade das jurisdições e no poder-dever do Estado de exercer sua própria jurisdição penal. ${ }^{9}$ O Preâmbulo do Estatuto de Roma não traz consigo, portanto, considerações acerca do fim do poder soberano dos Estados, mas sim, a questão dos contornos e dos limites da soberania na sociedade internacional contemporânea. ${ }^{10}$

\section{As normas de cooperação do estatuto de Roma}

A cooperação dos Estados condiciona a efetividade do procedimento judicial do Tribunal Penal Internacional, sendo para ele uma necessidade. A obrigação de cooperar de um Estado perante o Tribunal concretiza a aspiração a uma justiça penal internacional e, dessa forma, deve ser conciliada com a realidade da sociedade internacional. A obrigação de cooperar não é homogênea: seus elementos variam em função da origem da jurisdição, do aspecto da cooperação e do destinatário da obrigação levada em conta. ${ }^{11}$

Os termos e as condutas de cooperação requeridas podem variar de acordo com a origem da jurisdição do Tribunal Penal Internacional sobre um caso. Essa

9 CASSESE, Antonio. The Statute of the International Criminal Court: some preliminary reflections. European Journal of International Law, Oxford, v. 10, n.1, p. 144-171, may 1999.

${ }^{10}$ PERRONE-MOISÉS, Cláudia. O princípio da complementaridade no Estatuto do Tribunal Penal Internacional e a soberania contemporânea. Revista Política Externa, v. 8, n. 4, p. 3-11, mar./maio 2000.

${ }^{11}$ UBÉDA, Muriel. L'Obligation de coopérer avec les juridictions internationales. In: ASCENSIO, Hervé; DECAUX, Emmanuel; PELLET Alain (Org.) Droit international penal. Paris : A. Pedone, 2000. p. 951-967. 
jurisdição pode derivar de um tratado internacional (um acordo de jurisdição "ad hoc" entre um Estado e o Tribunal) de uma resolução do Conselho de Segurança da Organização das Nações Unidas (determinando ao Tribunal a tarefa de investigar uma situação em que haja a grave suspeita da ocorrência de um dos crimes sob sua competência) ou do próprio Estatuto de Roma, quando se trate do exercício da jurisdição complementar em um Estado Parte.

Em relação ao aspecto da cooperação demandado pelo Tribunal, o Estatuto de Roma estabeleceu a cooperação internacional sob três aspectos: cooperação legislativa, cooperação administrativa judicial e cooperação executória. A cooperação legislativa refere-se à relação vertical entre o Tribunal e a Estado Parte, dizendo respeito à obrigação deste em prever em sua ordem jurídica norma que regulamente as formas de cooperação previstas no Estatuto de Roma. Dentro do Capítulo IX do Estatuto, a cooperação legislativa encontra-se presente de forma específica no Artigo 88, o qual será visto adiante.

A cooperação executória refere-se ao cumprimento das penas impostas pelo Tribunal nos Estados que aceitaram receber os indivíduos condenados, chamados de Estados de detenção. ${ }^{12}$ A cooperação executória é objeto do Capítulo X do Estatuto de Roma.

A cooperação administrativa judicial, por sua vez, diz respeito à relação entre o Tribunal e o Estado Parte no interesse de uma investigação ou do andamento de um processo, incluindo a entrega de pessoas ao Tribunal, a prisão preventiva de um indivíduo ou a realização de outras formas de cooperação. É tratada de forma específica nos artigos do Capítulo IX do Estatuto de Roma.

Quanto aos destinatários da obrigação, as relações de cooperação poderão ser entre o Tribunal Penal Internacional e um Estado ou entre o Tribunal e uma organização internacional. As relações de cooperação entre tribunais internacionais

\footnotetext{
${ }^{12}$ HIZUME, Gabriella de Camargo. Breves reflexões acerca da questão da cooperação jurídica no Tribunal Penal Internacional. In: MENEZES, Wagner (Coord.). Estudos de direito internacional: anais do $5^{\circ}$ Congresso Brasileiro de Direito Internacional. Curitiba: Juruá, 2007. p. 187-193. v. 5.
} 
e organizações internacionais têm sido importantes para a captura de criminosos e a preservação de provas. Para Louise Arbour, ex-Promotora do Tribunal "Ad Hoc" para a Ex-Iugoslávia, a atuação de soldados de alianças militares sob o pálio da ONU em intervenções de cunho humanitário não lhes retira a neutralidade inerente ao mandato dessas organizações, porque se fundamenta no respeito ao Direito Humanitário e a normas de Direitos Humanos consideradas vinculantes pela Direito Internacional. ${ }^{13}$

Durante a Conferência Internacional que redigiu o Estatuto de Roma, as discussões sobre as normas de cooperação judicial com o Tribunal foram excessivamente condicionadas por considerações políticas. ${ }^{14} \mathrm{O}$ fato de algumas normas sobre cooperação disporem sobre a concretização da jurisdição complementar do Tribunal sobre os Estados conduziu os debatedores a duas posições bem delineadas: a primeira dizia respeito a um modelo de cooperação semelhante ao da cooperação judicial entre Estados, que respeitasse plenamente a soberania. ${ }^{15}$ Nesse modelo, o Tribunal não teria autoridade sobre os Estados na execução dos atos relacionados aos indivíduos que se encontram sob sua soberania, não os podendo forçar a cooperarem e esperando que estes exerçam por si mesmos a persecução criminal requerida. ${ }^{16}$

A segunda posição diferenciava a cooperação judicial entre Estados, considerando-a uma relação jurídica de natureza horizontal, da cooperação judicial entre um Estado e o Tribunal Penal Internacional, a qual, nos termos do princípio

${ }^{13}$ ARBOUR, Louise. The international tribunals for serious violations of international humanitarian law in the former Yugoslavia and Rwanda. McGill Law Journal, Montreal, n. 46, p. 195-201, 2000.

${ }^{14}$ KREB, Claus. Penas, execução e cooperação no estatuto para o Tribunal Penal Internacional. In: HOUKR, Fauzi Hassan; AMBOS, Kai. Tribunal penal internacional. São Paulo: Revista dos Tribunais, 2000. p. 125-147.

${ }^{15}$ KREB, Claus. Penas, execução e cooperação no estatuto para o Tribunal Penal Internacional. In: HOUKR, Fauzi Hassan; AMBOS, Kai. Tribunal penal internacional. São Paulo: Revista dos Tribunais, 2000. p. 125-147.

${ }^{16}$ CASSESE, Antonio. The Statute of the International Criminal Court: some preliminary reflections. European Journal of International Law, Oxford, v. 10, n.1, p. 144-171, May 1999. 
da complementaridade, deveria ser considerada uma relação jurídica vertical. ${ }^{17}$ Partiria do modelo tradicional de cooperação para uma estrutura "supraestatal", na qual o Tribunal teria autoridade não apenas para exercer a persecução penal diretamente no território do Estado, mas também emitindo documentos vinculantes contra o próprio Estado com previsão de sanções em caso de não cumprimento. Nesse modelo o Estado não teria direito de reter as provas colhidas nem se recusar a divulgar informações ou executar prisões determinadas pelo Tribunal. Esse modelo é baseado na atuação dos Tribunais Internacionais “Ad Hoc” da ex-Iugoslávia e de Ruanda. ${ }^{18}$

Essa polarização foi contornada com um modelo conciliatório que busca evitar o confronto direto entre o Tribunal e o Estado na esfera da cooperação judicial. As omissões presentes no Estatuto de Roma, no entanto, autorizam dizer que o modelo de cooperação adotado aproxima-se mais com a visão tradicional de cooperação judicial, ou de uma relação jurídica de natureza horizontal, do que com a ideia de uma jurisdição que, com sua natureza complementar, estabeleceria uma relação jurídica vertical do Tribunal com os Estados.

Os Tribunais "Ad Hoc" do Conselho de Segurança da ONU possuíam primazia de jurisdição e as Resoluções 827 e 955 do Conselho de Segurança exigiam dos Estados membro da ONU plena cooperação com seu trabalho. ${ }^{19}$ Já o Tribunal Penal Internacional, através do modo pelo qual o Estatuto de Roma foi redigido, caracteriza-se por um modelo de cooperação moldado por seus próprios membros e não imposto por um órgão externo. Tal fato, por um lado, permitiu que os redatores do Estatuto de Roma elaborassem de forma mais precisa as relações de cooperação do Tribunal Penal Internacional e, por outro, reduziram seus poderes

${ }^{17}$ KREB, Claus. Penas, execução e cooperação no estatuto para o Tribunal Penal Internacional. In: HOUKR, Fauzi Hassan; AMBOS, Kai. Tribunal penal internacional. São Paulo: Revista dos Tribunais, 2000. p. 125-147.

${ }^{18}$ CASSESE, Antonio. The Statute of the International Criminal Court: some preliminary reflections. European Journal of International Law, Oxford, v. 10, n.1, p. 144-171, May 1999.

${ }^{19}$ BUCHET, Antoine. Le transfert devant les juridictions internationals. In: ASCENSIO, Hervé; DECAUX, Emmanuel; PELLET, Alain (Org.) Droit international penal. Paris : A. Pedone, 2000. p. 969-980. 
em relação aos destinatários de seus requerimentos de cooperação em comparação com as normas de cooperação dos Tribunais "Ad Hoc" da ex-Iugoslávia e de Ruanda e, assim, a própria capacidade de atuar do principal órgão da Justiça Internacional Penal. ${ }^{20}$

Como resultado, observa-se que, em quase oito anos de funcionamento, nenhum processo foi concluído e a maior parte dos acusados permanece livre e impune. A postura da Procuradoria do Tribunal, inicialmente conciliatória, respeitosa perante a soberania estatal, mudou para a confrontação com os Estados onde os crimes ocorreram e para a denúncia da falta de cooperação dos demais Estados da comunidade internacional na repressão desses crimes. ${ }^{21}$ Em resposta, a atuação do Tribunal Penal Internacional tem sido acusada nos meios diplomáticos e pela doutrina de ser um desincentivo à paz nesses Estados. ${ }^{22}$ Desse modo, o estudo do Capítulo IX do Estatuto de Roma, que trata sobre a matéria, revela-se fundamental para a instituição.

\section{A obrigação geral de cooperar}

O artigo 86 dispõe que o Estado Parte tem a obrigação de cooperar plenamente com o Tribunal no inquérito e nos procedimentos contra crimes de competência do Tribunal. ${ }^{23}$ Essa obrigação geral desdobra-se em várias obrigações específicas que se desenvolvem nos artigos subsequentes e nas Regras de Procedimento

${ }^{20} \mathrm{ZHOU}, \mathrm{Han}-\mathrm{Ru}$. The enforcement of arrest warrants by the International Forces: from the ICTY to the ICC. Journal of International Criminal Justice, Oxford, v. 4, n. 2, p. 202-218, November 2005.

${ }^{21}$ PESKIN, Victor. Caution and confrontation in the International Criminal Court's pursuit of accountability in Uganda and Sudan. Human Rights Quarterly, Cincinnati, v. 31, n. 3, p. 655-691, August 2009.

22 AKHAVAN, Payam. Are International Criminal Tribunals a disincentive to peace?: Reconciling judicial romantism with political realism. Human Rights Quarterly, Cincinnat, n. 31, p. 624-654, 2009.

${ }^{23}$ BRASIL. Decreto $n^{\circ}$ 4388/2002 (Estatuto de Roma). Disponível em: <www.planalto.gov. br>. Acesso em: 13 abr. 2010. Artigo 86: Obrigação Geral de Cooperar. Os Estados Partes deverão, em conformidade com o disposto no presente Estatuto, cooperar plenamente com o Tribunal no inquérito e no procedimento contra crimes da competência deste. 
e Prova do Tribunal. ${ }^{24}$ Mesmo sendo verdade que a simples aceitação de que existe uma obrigação internacional do Estado em cooperar com o Tribunal já seja um elemento relevante, ${ }^{25} \mathrm{o}$ princípio afirmado no artigo 86 é pouco eficaz porque não possui uma sanção que o garanta.

O artigo 87 foi redigido de forma semelhante ao artigo 29 do Estatuto do Tribunal Penal Internacional "Ad Hoc" para a ex-Iugoslávia ${ }^{26}$, embora o termo original que determinava o caráter vinculante da cooperação, ordem (“order”), tenha sido substituído no artigo do Estatuto de Roma para pedido ("request"), entendido como não vinculante. ${ }^{27}$

O artigo 87 (6) trata do relacionamento com o Tribunal Penal Internacional e as organizações intergovernamentais. ${ }^{28} \mathrm{O}$ parágrafo determina que "O Tribunal poderá solicitar informações ou documentos a qualquer organização governamental". Os termos em que a cooperação pode ser requerida e o tratamento jurídico do assunto dado por esse parágrafo não condiz com a importância do tema

${ }^{24}$ UBÉDA, Muriel. L'Obligation de coopérer avec les juridictions internationales. In: ASCENSIO, Hervé, DECAUX, Emmanuel; PELLET Alain (Org.) Droit international penal. Paris: A. Pedone, 2000. p. 951-967.

${ }^{25}$ NSEREKO, Daniel N. Genocidal conflict in Rwanda and the ICTR. Netherlands International Law Review. Hague. v. 48, n.1. p.31-65, Mar. 2001.

${ }^{26}$ Statute of the International Tribunal for the Prosecution of Persons Responsible for Serious Violations of International Humanitarian Law Committed in the Territory of the Former Yugoslavia since 1991. Article 29: Cooperation and judicial assistance. 1. States shall cooperate with the International Tribunal in the investigation and prosecution of persons accused of committing serious violations of international humanitarian law. 2 . States shall comply without undue delay with any request for assistance or an order issued by a Trial Chamber, including, but not limited to:(a) the identification and location of persons;(b) the taking of testimony and the production of evidence;(c) the service of documents; (d) the arrest or detention of persons; (e) the surrender or the transfer of the accused to the International Tribunal. (grifo nosso).

$27 \mathrm{ZHOU}, \mathrm{Han}-\mathrm{Ru}$. The enforcement of arrest warrants by the International Forces: from the ICTY to the ICC. Journal of International Criminal Justice, Oxford, v. 4, n.2, p. 202-218, Nov. 2005.

${ }^{28}$ BRASIL.Decreto $n^{\circ}$ 4388/2002 (Estatuto de Roma). Artigo 87 [...] Disponível em: <www. planalto.gov.br>. Acesso em: 13 abr. 2010. O Tribunal poderá solicitar informações ou documentos a qualquer organização intergovernamental. Poderá igualmente requerer outras formas de cooperação e auxílio a serem acordadas com tal organização e que estejam em conformidade com a sua competência ou com seu mandato. 
para o Tribunal Penal Internacional. As organizações intergovernamentais têm protagonizado as intervenções humanitárias desde a década de noventa do século passado: a Organização dos Estados Americanos interveio no Haiti, a União Africana mantém tropas em Darfur e a Organização do Tratado do Atlântico Norte, a OTAN, participou ativamente da intervenção nos Bálcãs. ${ }^{29}$ As organizações internacionais envolvidas em intervenções humanitárias são, portanto, atores internacionais cujo papel é determinante para o sucesso da atuação do Tribunal Penal Internacional em Estados cujo Poder Judiciário entrou em colapso. Dessa forma, assim como foi determinante para os tribunais "ad hoc", seria fundamental para o Tribunal Penal Internacional emitir mandados com força vinculante em relação às organizações intergovernamentais sempre que os membros dessas organizações que estivessem envolvidos na intervenção fossem Estados Partes. No entanto, o artigo 87 (6) afirma que outras formas de cooperação e auxílio - além da prestação de informações e documentos - deverão ser objeto de acordo entre o Tribunal e a organização. Esse parágrafo, além de contrariar a prática do Tribunal Penal Internacional "Ad Hoc" para a ex-Iugoslávia, que ainda se encontra em operação, cria a estranha situação de o Tribunal poder requerer um ato de cooperação da França, enquanto Estado Parte, mas não poder requerer o mesmo ato de uma operação da OTAN em relação à zona controlada pelo exército francês. Han-Ru Zhou salienta que essa disposição do Estatuto enfraquece o Tribunal Penal Internacional porque não cria obrigação internacional e, assim, permite às organizações intergovernamentais - cujos líderes militares são relutantes em arriscar seus soldados em operações no interesse da justiça internacional - recusarem cooperação sem enfrentarem a responsabilização internacional..$^{30}$

Outro problema relativo à obrigação de cooperar estabelecida pelo Estatuto é a falta de previsão de sanção específica para o descumprimento indevido de um Estado a um pedido de cooperação feito pelo Tribunal Penal Internacional. O arti-

${ }^{29} \mathrm{ZHOU}, \mathrm{Han}-\mathrm{Ru}$. The enforcement of arrest warrants by the International Forces: from the ICTY to the ICC. Journal of International Criminal Justice, Oxford v. 4, n. 2, p. 202-218, Nov. 2005.

${ }^{30} \mathrm{ZHOU}, \mathrm{Han}-\mathrm{Ru}$. The enforcement of arrest warrants by the International Forces: from the ICTY to the ICC. Journal of International Criminal Justice, Oxford, v. 4, n. 2, p. 202-218, Nov. 2005. 
go $87(7)^{31}$ dispõe que a recusa ao pedido de cooperação será relatada à Assembleia dos Estados Partes ou ao Conselho de Segurança, quando o pedido de cooperação for relativo a um caso cuja origem se encontra em uma denúncia ("referral") do Conselho de Segurança ao Tribunal. Tal medida se apresenta como inócua, pois o artigo 112, (2), alínea "f" do Estatuto, que concede competência à Assembleia dos Estados Partes para apreciar a não cooperação de um Estado a um pedido do Tribunal, não prevê a aplicação de qualquer sanção ao Estado não cooperante. ${ }^{32}$ Quanto ao Conselho de Segurança da ONU, seu comportamento em relação aos atos de não cooperação sofridos pelos seus próprios Tribunais "Ad Hoc" para Ruanda e para a ex-Iugoslávia nunca autorizou a imaginar-se que haveria qualquer pronta reação de sua parte a um relatório do Tribunal Penal Internacional. ${ }^{33}$ Ressalte-se que, em caso de investigação originada pela denúncia de um Estado Parte ou pela iniciativa própria do Procurador, não existe nem mesmo a possibilidade de comunicação ao Conselho de Segurança.

Dispondo sobre a cooperação legislativa, o artigo 88 prevê expressamente que os Estados Partes deverão assegurar-se de que o seu direito interno preveja procedimentos que permitam responder as formas de cooperação especificadas no

${ }^{31}$ BRASIL. Decreto $n^{\circ}$ 4388/2002 (Estatuto de Roma). Artigo 87 [...] Disponível em www. planalto.gov.br Acesso em 13/04/2010. Se, contrariamente ao disposto no presente Estatuto, um Estado Parte recusar um pedido de cooperação formulado pelo Tribunal, impedindo-o assim de exercer seus poderes e funções nos termos do presente Estatuto, o Tribunal poderá elaborar um relatório e remeter a questão à Assembleia dos Estados Partes ou ao Conselho de Segurança, quando tiver sido este a submeter o fato ao Tribunal.

32 BRASIL. Decreto $n^{\circ}$ 4388/2002 (Estatuto de Roma). Artigo 87 [...] Disponível em www. planalto.gov.br Acesso em 13/04/2009. Artigo 112: Assembleia dos Estados Partes. 1. É constituída, pelo presente instrumento, uma Assembleia dos Estados Partes. Cada um dos Estados Partes nela disporá de um representante, que poderá ser coadjuvado por substitutos ou assessores. Outros Estados signatários do Estatuto ou da Ata Final poderão participar dos trabalhos da assembleia na qualidade de observadores. 2. A Assembleia: [...] examinará em harmonia com os parágrafos $5^{\circ}$ e $7^{\circ}$ do artigo 87 qualquer questão relativa à não cooperação dos Estados.

${ }^{33}$ CIAMPI, Annalisa. Sull'applicazione della teoria dei poteri impliciti da parte del Tribunale Penale Internazionale per la ex-Iugoslavia. Rivista di Diritto Internazionale, Milano, v. 81. n. 1, p. 130-146, jun. 1998. 
Capítulo IX do Estatuto ${ }^{34}$, porém, poucos Estados cumpriram com essa obrigação até o presente momento. ${ }^{35}$ Esse fato torna as relações entre o Tribunal e os Estados Partes complexas devido à necessidade de se estabelecer nas legislações nacionais a diferença entre os institutos da extradição e da entrega.

\section{1 A entrega de pessoas ao tribunal}

Para o funcionamento do Tribunal Penal Internacional, é preciso que os indivíduos acusados de praticarem os crimes sob sua competência efetivamente se apresentem para o julgamento, visto que o Tribunal não julga pessoas à revelia. Desse modo, é necessário um procedimento que assegure a detenção e aprisionamento do acusado. Isso só ocorrerá se o Estado Parte em cujo território o indivíduo se encontre, cumpra a ordem de detenção expedida pelo Tribunal e o entregue para julgamento. Para evitar os vários obstáculos inerentes ao tradicional instituto da extradição, o artigo 102 do Estatuto de Roma diferencia a extradição, ou seja, "a entrega de uma pessoa por um Estado a outro Estado conforme previsto em um tratado, em uma convenção ou no direito interno", da entrega, o que significa a "entrega de uma pessoa por um Estado ao Tribunal nos termos do presente Estatuto". Enquanto a extradição pressupõe a reciprocidade inerente às relações entre Estados, a entrega corresponde à concretização de um Tratado assinado entre um Estado e uma organização internacional. ${ }^{36}$ Assim, a adoção do instituto da entrega se deve a dois argumentos. Em primeiro lugar, a jurisdição do Tribunal Penal Internacional é complementar e permite aos Estados perseguir e julgar o indivíduo se não quiser entregá-lo ao Tribunal, possibilidade inexistente no caso da extradição

\footnotetext{
${ }^{34}$ BRASIL. Decreto $n^{\circ}$ 4388/2002 (Estatuto de Roma). Artigo 88 [...] Disponível em: <www. planalto.gov.br>. Acesso em 13 abr. 2010. Procedimentos previstos no direito interno. Os Estados Partes deverão assegurar-se que o seu direito interno prevê procedimentos que permitem responder a todas as formas de cooperação especificadas nesse Capítulo.

35 OOSTERVELD, Valerie; PERRY, Mike; McManus, John. The Cooperation of States with the International Criminal Court. Fordham International Law Journal, v. 25, n. 3, p. 767839, mar. 2002.

${ }^{36}$ MIRANDA, Jorge. A incorporação ao direito interno de instrumentos jurídicos de direito internacional humanitário e direito internacional dos direitos humanos. Revista CEJ, $\mathrm{n}$. 11, p. 23-26, maio/ago. 2000.
} 
devido à existência de uma jurisdição estrangeira. Em segundo lugar, sendo a jurisdição da entrega complementar e não estrangeira, é desnecessário que o Estado exerça vários procedimentos relativos ao juízo da extradição, no tocante à identificação, na jurisdição estrangeira dos elementos do crime e dos princípios gerais do Direito Penal semelhantes à jurisdição doméstica. ${ }^{37}$

No entanto, em relação à operacionalização do instituto da entrega de pessoas ao Tribunal, cujo procedimento está previsto entre os artigos 89 e 91, existem dificuldades não contornadas pelas regras de cooperação existentes. O Estatuto determina para o Tribunal Penal Internacional uma situação jurídica inferior ao Estado requerido em comparação àquela existente para os Tribunais "Ad Hoc" da ex-Iugoslávia e de Ruanda. O artigo 90 dispõe que, no caso de um Estado Parte receber pedidos concorrentes de entrega do Tribunal e de um terceiro Estado que não seja signatário do Estatuto de Roma, por exemplo, o Estado Parte requerido poderá optar entre satisfazer o pedido de entrega ao Tribunal ou de extradição ao terceiro Estado ${ }^{38}$. O Tribunal só poderá alegar preferência se o Estado requerido não estiver obrigado por acordo de extradição com o terceiro Estado requerente

${ }^{37}$ KREB, Claus. Penas, execução e cooperação no estatuto para o Tribunal Penal Internacional. In: HOUKR, Fauzi Hassan; AMBOS, Kai. Tribunal penal internacional. São Paulo: Revista dos Tribunais, 2000. p. 125-147.

${ }^{38}$ BRASIL. Decreto $n^{\circ}$ 4388/2002 (Estatuto de Roma). Artigo 87 [...] Disponível em: $<$ www.planalto.gov.br>. Acesso em 13 abr. 2010. Artigo 90: Pedidos concorrentes. Um Estado Parte que, nos termos do artigo 89, receba um pedido de entrega de uma pessoa formulado pelo Tribunal e receba, igualmente, de qualquer outro Estado, um pedido de extradição relativo à mesma pessoa, pelos mesmos fatos que motivaram o pedido de entrega por parte do Tribunal, deverá notificar o Tribunal e o Estado requerente de tal fato [...] 4. Se o Estado requerente não for Parte no presente Estatuto o Estado requerido, desde que não esteja obrigado por uma norma internacional a extraditar o acusado para o Estado requerente, dará prioridade ao pedido de entrega formulado pelo Tribunal, no caso de este se ter decidido pela admissibilidade do caso [...] Relativamente aos casos em que o disposto no parágrafo $4^{\circ}$ seja aplicável, mas o Estado requerido se veja obrigado, por força de uma norma internacional, a extraditar a pessoa para o Estado requerente que não seja Parte no presente Estatuto, o Estado requerido decidirá se procederá a entrega da pessoa em causa ao Tribunal ou se a extraditará para o Estado requerente. Na sua decisão, o Estado requerido terá em conta todos os fatores relevantes incluindo, entre outros: a) A ordem cronológica dos pedidos; b) Os interesses do Estado requerente incluindo, se relevante, se o crime foi cometido no seu território bem como a nacionalidade das vítimas e da pessoa reclamada; e c) A possibilidade do Estado requerente proceder posteriormente à entrega da pessoa ao Tribunal. 
(privilégio que caberia a qualquer Estado que tivesse um acordo de extradição) ou em casos específicos em que o pedido concorrente for originário de um Estado Parte e a situação sob investigação já tiver sido admitida pela Câmara de Questões Preliminares. ${ }^{39}$ Os tribunais "ad hoc" possuíam primazia de jurisdição em quaisquer desses casos. Seria natural, desse modo, que, existindo um conflito de jurisdição entre um Estatuto que estabelece uma jurisdição universal, contanto que complementar, sobre um tratado bilateral de extradição ou, mesmo, considerando a missão do Tribunal de implementar a justiça internacional penal no interesse da paz e segurança internacional, que a primazia em julgar o indivíduo acusado coubesse ao Tribunal Penal Internacional. ${ }^{40}$

O artigo 91 (2), “c”, prevê que o Estado crie um procedimento em separado para a entrega de indivíduos ao Tribunal Penal Internacional ou adapte o procedimento de extradição existente, desde que esse procedimento não seja mais restritivo do que o procedimento da extradição. ${ }^{41}$ A Regra 184 das Regras de Procedimento e Prova determina o dever do Estado informar imediatamente o Secretário do Tribunal Penal Internacional no caso dos indiciados estarem prontos para

${ }^{39}$ HIZUME, Gabriella de Camargo. Breves reflexões acerca da questão da cooperação jurídica no Tribunal Penal Internacional. In: MENEZES, Wagner (Coord.). Estudos de direito internacional: anais do $5^{\circ}$ Congresso Brasileiro de Direito Internacional. Curitiba: Juruá, 2007. p. 187-193, v. 5.

${ }^{40}$ CASSESE, Antonio. The Statute of the International Criminal Court: some preliminary reflections. European Journal of International Law, Oxford v. 10, n.1, p. 144-171, May 1999.

${ }^{41}$ BRASIL. Decreto $n^{\circ}$ 4388/2002 (Estatuto de Roma). Artigo 87 [...] Disponível em: <www. planalto.gov.br>. Acesso em 13 abr. 2010. Artigo 91. Conteúdo de pedido de detenção e de entrega. [...] O pedido de detenção e de entrega de uma pessoa relativamente à qual o Juízo de Instrução tiver emitido um mandado de detenção ao abrigo do artigo 58 deverá conter ou ser acompanhando dos seguintes documentos: [...]. c) Os documentos, declarações e informações necessários para satisfazer os requisitos do processo de entrega pelo Estado requerido; contudo tais requisitos não poderão ser mais rigorosos do que os que devem ser observados em caso de um pedido de extradição em conformidade com tratados ou convênios celebrados entre o Estado requerido e outros Estados, devendo, se possível, ser menos rigorosos face à natureza específica de que se reveste o Tribunal. 
a entrega. ${ }^{42}$ Embora o Estado Parte deva responder "sem demora" ao pedido de cooperação que receber do Tribunal, o pedido de entrega será transmitido pela via tradicional diplomática ${ }^{43}$ e os Estados são livres para determinar o procedimento e quais órgãos ficarão responsáveis pela cooperação. ${ }^{44}$

\section{2 Cooperação em matéria de prova}

Por cooperação em matéria de prova se entende a preservação, a disposição e a transmissão dos elementos de prova em uma investigação. Assim, de forma geral, os destinatários da obrigação devem assistir a Procuradoria a estabelecer a materialidade dos fatos e, através de sua colaboração, permitir que os órgãos dos tribunais internacionais atuem em seu território nacional. ${ }^{45}$ Previstos no artigo 93, dentro do primeiro parágrafo, esses atos de cooperação incluem produção de provas, interrogatórios, notificações, envio de testemunhas ou peritos, transferências temporárias, exumação de cadáveres em valas comuns, buscas e apreensões e qualquer outra for-

${ }^{42}$ INTERNATIONAL CRIMINAL COURT. Assembly of States Parties. Rules of procedure and evidence. rule 184: Arrangements for surrender 1. The requested State shall immediately inform the Registrar when the person sought by the Court is available for surrender $[\ldots]$

${ }^{43}$ OOSTERVELD, Valerie; PERRY, Mike; McManus, John. The Cooperation of States with the International Criminal Court. Fordham International Law Journal, [S. 1.] v. 25, n. 3, p. 767-839, mar. 2002.

${ }^{44}$ BUCHET, Antoine. Le transfert devant les juridictions internationals. In: ASCENSIO, Hervé; DECAUX, Emmanuel; PELLET, Alain (Org.) Droit international penal. Paris: A. Pedone, 2000. p. 969-980.

${ }^{45}$ UBÉDA, Muriel. L'Obligation de coopérer avec les juridictions internationales. In: ASCENSIO, Hervé, DECAUX, Emmanuel; PELLET Alain (Org.) Droit international penal. Paris : A. Pedone, 2000. p. 951-967.

${ }^{45}$ BRASIL. Decreto $n^{\circ}$ 4388/2002 (Estatuto de Roma). Artigo 87 [...] Disponível em: <www. planalto.gov.br>. Acesso em 13/04/2010. Artigo 93. Outras formas de cooperação. 1. Em conformidade com o disposto no presente Capítulo e nos termos dos procedimentos previstos nos respectivos direitos internos, os Estados Partes darão seguimento aos pedidos formulados pelo Tribunal para a concessão de auxílio no âmbito de inquéritos ou procedimentos criminais no que se refere a: a) Identificar uma pessoa e o local onde se encontra, ou localizar objetos; b) Reunir elementos de prova, incluindo os depoimentos prestados sob juramento, bem como produzir elementos de prova, incluindo perícias e relatórios de que o Tribunal necessita; c) Interrogar qualquer pessoa que seja objeto 
ma lícita de auxílio que possa facilitar o inquérito ou o julgamento. ${ }^{46}$ Infelizmente, o Estatuto de Roma não especifica se a coleta de provas e a execução de intimações em mandados serão empreendidas pelo pessoal da Procuradoria do Tribunal Penal Internacional ou se será executada pelo Estado a pedido do Promotor. Com a insistência do Estatuto em buscar concordância com as legislações nacionais, não se surpreende que a leitura oficial do Estatuto seja a segunda opção, a não ser em casos especiais, como os previstos no artigo 99, o qual será analisado abaixo. ${ }^{47}$

As formas dos Estados escaparem à cooperação, todavia, são tão numerosas quanto às maneiras de cooperar com o Tribunal. O Estado pode recusar o auxílio alegando que a medida fere princípio geral de sua legislação ou que a divulgação ou a produção de um documento vai contra seus interesses de segurança nacional. Pode ainda impor condições para a concessão de um auxílio e, no caso de transferência temporária de uma pessoa detida para fins de identificação, será necessário que não só o Estado, mas a própria pessoa consinta com o ato de cooperação. Ou seja, o Tribunal não pode obrigar testemunhas a comparecerem ao procedimento. ${ }^{48} \mathrm{O}$ artigo 93 (4) determina que um Estado Parte poderá recusar, no todo ou em parte, um pedido de auxílio se tal pedido se reportar à produção de documentos ou elementos

de inquérito ou de procedimento criminal; d) Notificar documentos, nomeadamente documentos judiciários; e) Facilitar o comparecimento voluntário, perante o Tribunal, de pessoas que deponham na qualidade de testemunhas ou de peritos; f) Proceder à transferência temporária de pessoas, em conformidade com o parágrafo $7^{\circ} ; \mathrm{g}$ ) Realizar inspeções, nomeadamente a exumação e o exame de cadáveres enterrados em fossas comuns; h) Realizar buscas e apreensões; i) Transmitir registros e documentos, nomeadamente registros e documentos oficiais; j) Proteger vítimas e testemunhas, bem como preservar elementos de provas; k) Identificar, localizar e congelar, ou apreender o produto de crimes, bens, haveres e instrumentos ligados aos crimes, com vista à sua eventual declaração de perda, sem prejuízo de terceiros de boa fé; e l) Prestar qualquer outra forma de auxílio não proibida pela legislação do Estado requerido, destinada a facilitar o inquérito e o julgamento por crimes da competência do Tribunal.

${ }^{47}$ CASSESE, Antonio. The Statute of the International Criminal Court: some preliminary reflections. European Journal of International Law, Oxford, v. 10, n.1, p. 144-171, may 1999.

${ }^{48}$ KREB, Claus. Penas, execução e cooperação no estatuto para o Tribunal Penal Internacional. In: HOUKR, Fauzi Hassan; AMBOS, Kai. Tribunal penal internacional. São Paulo: Revista dos Tribunais, 2000. p. 125-147. 
de prova que ponham em risco sua segurança nacional, ${ }^{49}$ nos termos do artigo 72 do Estatuto. ${ }^{50} \mathrm{O}$ artigo 72 é baseado na decisão da Câmara de Apelação do Tribunal Penal Internacional "Ad Hoc" para a ex-Iugoslávia relativa ao Caso Blaskic. ${ }^{51}$ Mas, para Antônio Cassese, enquanto aquela decisão visava criar um mecanismo para o acesso ao máximo de informação possível pelo Tribunal, o artigo 72 tem sentido contrário, concedendo todas as salvaguardas ao Estado ${ }^{52}$ Além dessas disposições presentes no artigo 93, o Estado poderá ainda, nos termos do artigo 94, suspender uma medida de cooperação, alegando que a execução dessa medida estaria atrapalhando o curso de outro procedimento criminal por ele realizado. ${ }^{53}$ Finalmente, o Estado poderá, nos termos do artigo 97, consultar o Tribunal, quando entender que o cumprimento do

${ }^{49}$ BRASIL. Decreto $n^{\circ}$ 4388/2002 (Estatuto de Roma). Artigo 87 [...] Disponível em: <www. planalto.gov.br>. Acesso em 13 abr. 2010. Artigo 93. Outras formas de cooperação. [...] 4. Nos termos do disposto no artigo 72 um Estado Parte só poderá recusar, no todo ou em parte, um pedido de auxílio formulado pelo Tribunal se tal pedido se reportar unicamente à produção de documentos ou a divulgação de elementos de prova que atentem contra a sua segurança nacional.

${ }^{50}$ BRASIL. Decreto no 4388/2002 (Estatuto de Roma). Artigo 87 [...] Disponível em: <www. planalto.gov.br>. Acesso em 13 abr. 2010. Artigo 72. Proteção de informação relativa à segurança nacional. 1. O presente artigo aplicar-se-á a todos os casos em que a divulgação de informação ou de documentos de um Estado possa no entender deste, afetar os interesses de sua segurança nacional [...] 2. O presente artigo aplicar-se-á igualmente aos casos em que uma pessoa a quem tenha sido solicitada a prestação de informação ou provas, se tenha recusado a apresentá-las ou tenha entregado a questão ao Estado, invocando que tal divulgação afetaria os interesses de segurança nacional do Estado, e o Estado em causa confirme que, no seu entender, essa divulgação afetaria os interesses de sua segurança nacional.

${ }^{51}$ Nesse sentido vide: KING, Faiza Patel; LA ROSA, Anne Marie. Jurisprudence of the International Criminal Tribunal for the Former Yugoslavia. European Journal of International Law, [S. 1.], vol. 9, p. 759, 1998.

${ }^{52}$ CASSESE, Antonio. The Statute of the International Criminal Court: some preliminary reflections. European Journal of International Law, Oxford, v. 10, n. 3, p. 144-171, may 1999.

${ }^{53}$ BRASIL. Decreto no 4388/2002 (Estatuto de Roma). Artigo 87 [...] Disponível em: <www. planalto.gov.br>. Acesso em 13 abr. 2010. Artigo 94. Suspensão da execução de um pedido relativamente a um inquérito ou a procedimento criminal em curso. 1. Se a imediata execução de um pedido prejudicar o desenrolar de um inquérito ou de um procedimento criminal relativos a um caso diferente daquele a que se reporta o pedido, o Estado requerido poderá suspender a execução do pedido por tempo determinado, acordado com o Tribunal. Contudo, a suspensão não deve prolongar-se além do necessário para que o inquérito ou o procedimento criminal em causa sejam efetuados no Estado requerido. Este, antes de decidir suspender a execução do pedido, verificará se o auxílio não poderá ser concedido de imediato sob determinadas condições. 
pedido de cooperação, na forma em que se encontra, resulta em violação a tratado anteriormente celebrado com outro Estado. ${ }^{54}$

\section{3 A obrigação de cooperar frente às imunidades internacionais}

O polêmico artigo 98 do Estatuto dispõe que "o Tribunal pode não dar seguimento a um pedido de entrega ou de auxílio por força do qual o Estado requerido devesse atuar de forma incompatível com as obrigações que lhe incumbem à luz do Direito Internacional“, $\mathrm{em}^{55}$ matéria de imunidades ou de um acordo internacional. Assim, em relação às imunidades oficiais, existe um problema de delimitação: enquanto o artigo 27 determina que a capacidade oficial de um indivíduo não

${ }^{54}$ A BRASIL. Decreto $n^{\circ}$ 4388/2002 (Estatuto de Roma). Artigo 87 [...] Disponível em: $<$ www.planalto.gov.br>. Acesso em 13 abr. 2010. Artigo 97. Consultas. Sempre que, ao abrigo do presente Capítulo, um Estado Parte receba um pedido e verifica que este suscita dificuldades que possam obviar à sua execução ou impedi-la, o Estado em causa iniciará, sem demora, as consultas ao Tribunal com vistas à solução desta questão. Tais dificuldades poderão revestir tais formas: [...]

55 BRASIL. Decreto $n^{\circ}$ 4388/2002 (Estatuto de Roma). Artigo 87 [...] Disponível em: <www. planalto.gov.br>. Acesso em 13 abr. 2010. Artigo 98. Cooperação relativa à renúncia à imunidade ou ao consentimento na entrega. 1. O Tribunal pode não dar seguimento a um pedido de entrega ou de auxílio por força do qual o Estado requerido devesse atuar de forma incompatível com as obrigações que lhe incumbem à luz do direito internacional em matéria de imunidade dos Estados ou de imunidade diplomática de pessoa ou de bens de um Estado terceiro, a menos que obtenha previamente a cooperação desse Estado terceiro com vista ao levantamento da imunidade. 2. O Tribunal pode não dar seguimento a um pedido de entrega por força do qual o Estado requerido devesse atuar de forma incompatível com as obrigações que lhe incumbem em virtude de acordos internacionais à luz dos quais o consentimento do Estado de envio é necessário para que uma pessoa pertencente a este Estado seja entregue ao Tribunal, a menos que o Tribunal consiga, previamente, obter a cooperação do Estado de envio para consentir na entrega.

${ }_{55}$ BRASIL. Decreto $n^{\circ}$ 4388/2002 (Estatuto de Roma). Artigo 87 [...] Disponível em: <www. planalto.gov.br>. Acesso em 13 abr. 2010. Artigo 27. Irrelevância da qualidade oficial. 1. O presente Estatuto será aplicável de forma igual a todas as pessoas sem distinção alguma baseada na qualidade oficial. Em particular, a qualidade oficial de Chefe de Estado ou de Governo, de membro de Governo ou de Parlamento, de representante eleito ou de funcionário público, em caso algum eximirá a pessoa em causa de responsabilidade criminal nos termos do presente Estatuto, nem constituirá de per se motivo de redução da pena. 2. As imunidades ou normas de procedimento especiais decorrentes da qualidade 
o exime de sua responsabilidade, ${ }^{56}$ o artigo 98 afirma que as imunidades granjeadas pelo costume são aceitas pelo Estatuto. ${ }^{57} \mathrm{O}$ artigo 98 não é claro se o costume ou os tratados protegem nacionais de Estados que não são parte do Tribunal ou todos os Estados. Em verdade, esse artigo só faz sentido se for entendido que a imunidade em relação à jurisdição doméstica de um Estado não Parte é aplicável frente ao Tribunal, exigindo-se um acordo para exercício de jurisdição "ad hoc" ${ }^{58}$ Combinando-se a interpretação do artigo 98 com a do artigo 27, que dispõe sobre a irrelevância da capacidade oficial, parece, consequentemente, que um Estado seria obrigado a prender e entregar ao Tribunal seu próprio chefe de Estado, mas teria de respeitar a imunidade jurisdicional de um chefe de Estado estrangeiro. ${ }^{59}$

Uma interpretação sistemática do Estatuto de Roma, por outro lado, forçosamente deve impor limites a situações criadas a partir da aplicação do artigo 98. Se a jurisdição complementar estabelece que o dever do Estado seja julgar o indivíduo acusado pelos crimes sob a competência do Tribunal Penal Internacional ou entregá-lo para quem o faça, a questão a qual o artigo 98 propõe equacionar não é se o indivíduo será ou não julgado, mas, sim, por qual jurisdição será julgado. ${ }^{60}$ Além de consoante com o espírito do Estatuto, essa interpretação também é resultante dos termos do Preâmbulo da Convenção de Viena sobre Relações Diplomáticas, o qual afirma que “[...] os privilégios e imunidades concedidos a indivíduos não existem em seu benefício, mas para dar-lhes os meios de cumprir seus deveres

oficial de uma pessoa, nos termos do direito interno ou do direito internacional, não deverão obstar a que o Tribunal exerça a sua jurisdição sobre essa pessoa.

${ }^{57}$ PAULUS, Andreas L. The legalist groundwork of the International Criminal Court: commentaries on the Statute of the International Criminal Court. The European Journal of International Law, v. 14, n. 4, p. 843-860, Dec. 2003.

${ }^{58}$ PAULUS, Andreas L. The legalist groundwork of the International Criminal Court: commentaries on the Statute of the International Criminal Court. The European Journal of International Law, v. 14, n. 4, p. 843-860, Dec. 2003.

${ }^{59}$ BUCHET, Antoine. Le transfert devant les juridictions internationals. In: ASCENSIO, Hervé; DECAUX, Emmanuel; PELLET, Alain (Org.) Droit international penal. Paris: A. Pedone, 2000. p. 969-980.

${ }^{60}$ ZAPALLÀ, Salvatore. The reaction of the US to the entry into Force of the ICC Statute: comments on UN SC Resolution 1422 (2002) and article 98 agreements. Journal of International Criminal Justice, Florence, v. 13, n. 1, p. 114-134, Jan. 2002. 
de forma independente". ${ }^{61}$ Dessa forma, considerando que o Estatuto de Roma dispõe sobre a irrelevância de qualquer imunidade ou capacidade oficial, estas não poderão ser utilizadas para eximir o indivíduo da responsabilidade por seus atos, seja perante o Tribunal, seja perante um Estado e, uma interpretação que isentasse o indivíduo de sua responsabilidade, não tem validade perante o artigo 98. Da mesma forma, considerando que o principal objetivo do Estatuto é "por um fim à impunidade", as imunidades consubstanciadas pelo costume ou pelos acordos realizados entre terceiros Estados e Estados Parte do Tribunal, determinando a não entrega de indivíduos para julgamento ao Tribunal, só terão validade se garantirem que esses indivíduos efetivamente sejam levados à justiça pelo Estado requerente.62

\section{4 A execução de um pedido de cooperação em matéria de prova}

Por fim, o artigo 99, que determina quais medidas de auxílio serão executadas de acordo com a legislação interna do Estado requerido, destaca-se, sobretudo, pelo seu parágrafo quarto. Este dispõe que o Procurador poderá realizar um ato no interesse da investigação, diretamente no território do Estado Parte requerido, se não for necessário recorrer a medidas coercitivas, especialmente quando o Estado requerido for o Estado onde ocorreu o crime e o caso já tenha sido admitido pelo Tribunal (pa-

${ }^{61}$ Decreto no 56.435/65 (Convenção de Viena sobre Relações Diplomáticas). Preâmbulo [...] Disponível em: <www.planalto.gov.br>. Acesso em 13 abr. 2010. Reconhecendo que a finalidade de tais privilégios e imunidades não é beneficiar indivíduos, mas, sim, a de garantir eficaz desempenho das funções das missões diplomáticas, em seu caráter de representantes dos Estados.

${ }^{62}$ ZAPALLÀ, Salvatore. The reaction of the US to the entry into Force of the ICC Statute: comments on UN SC Resolution 1422 (2002) and article 98 agreements. Journal of International Criminal Justice, Florence, v.13, n.1, p. 114-134, Jan. 2002.

${ }^{62}$ BRASIL. Decreto $n^{\circ}$ 4388/2002 (Estatuto de Roma). Artigo 87 [...] Disponível em: <www. planalto.gov.br>. Acesso em 13 abr. 2010. Artigo 99. Execução dos pedidos apresentados ao abrigo dos artigos 93 e 96. [...] 4. Sem prejuízo dos demais artigos do presente Capítulo sempre que for necessário para a execução com sucesso de um pedido, e não haja que recorrer a medidas coercitivas, nomeadamente quando se trate de ouvir ou levar uma pessoa a depor, de sua livre vontade, mesmo sem a presença das autoridades do Estado Parte requerido se tal for determinante para a execução do pedido, ou quando se trate de examinar, sem proceder a alterações, um lugar público ou outro local público, o Procurador poderá dar cumprimento ao pedido diretamente no território de um Estado, de acordo com as seguintes modalidades: a) Quando o Estado requerido for o Estado 
rágrafo quarto, alínea "a”). ${ }^{63}$ Tal disposição do artigo 99 deve ser lida em consonância com o artigo 57 que, ao tratar dos poderes do Juízo de Instrução do Tribunal dispõe, em seu parágrafo terceiro, alínea "d", ${ }^{64}$ que o Procurador pode realizar medidas no território do Estado Parte em caso de quebra ou inexistência de autoridade estatal. ${ }^{65}$

O conteúdo do artigo 99 resume o diálogo que o modelo de cooperação previsto para o Tribunal Penal Internacional mantém com o princípio da complementaridade, que rege a jurisdição do Estatuto de Roma. O princípio da complementaridade determina que a jurisdição do Tribunal Penal Internacional deverá ser acionada no caso em que, ocorrendo um crime sob a competência do Tribunal, o Estado Parte, que deveria investigá-lo e reprimi-lo, for omisso ou estiver inoperante. No caso de um Estado inoperante, com seu Poder Judiciário em colapso, as regras de cooperação e investigação do Estatuto podem ser consideradas como um desdobramento dos artigos que regulam sua jurisdição complementar. Entretanto, quando o Estado é omisso ao seu dever de investigar e reprimir, as normas de cooperação e investigação do Estatuto determinam que o Tribunal necessita do seu consentimento para que o crime seja investigado e o caso seja julgado.

em cujo território haja indícios de ter sido cometido o crime e existir uma decisão sobre a admissibilidade tal como previsto nos artigos 18 e 19, o Procurador poderá executar diretamente o pedido, depois de ter levado a cabo consultas tão amplas quanto possível com o Estado requerido; b) Em outros casos, o Procurador poderá executar o pedido após consultas com o Estado Parte requerido em tendo em conta as condições ou as preocupações razoáveis que esse Estado tenha eventualmente argumentado. Sempre que o Estado requerido verificar que a execução de um pedido nos termos da presente alínea suscita dificuldades, consultará de imediato o Tribunal para resolver a questão [...]

${ }^{64}$ BRASIL. Decreto $n^{\circ}$ 4388/2002 (Estatuto de Roma). Artigo 57. Disponível em: <www. planalto.gov.br>. Acesso em 13 abr. 2010. Funções e poderes do juízo de instrução. 3. Independentemente de outras funções conferidas pelo Estatuto, o Juízo de Instrução poderá: [...] d) Autorizar o Procurador a adotar medidas específicas no âmbito de um inquérito, no território de um Estado Parte sem ter obtido a cooperação deste nos termos do disposto na Parte IX, caso o Juízo de Instrução determine que, tendo em consideração, na medida do possível, a posição do referido Estado, este último não está manifestamente em condições de satisfazer um pedido de cooperação face a incapacidade de todas as autoridades ou órgãos do seu sistema judiciário com competência para dar seguimento a um pedido de cooperação formulado nos termos do disposto na Parte IX.

${ }^{65}$ KREB, Claus. Penas, execução e cooperação no estatuto para o Tribunal Penal Internacional. In: HOUKR, Fauzi Hassan; AMBOS, Kai. Tribunal penal internacional. São Paulo: Revista dos Tribunais, 2000. p. 125-147. 
Esse padrão exposto no Capítulo IX tem consequências danosas a temas correlatos às relações de cooperação do Tribunal. Em relação à proteção das vítimas, o Estatuto de Roma adota uma postura inovadora e progressista no papel e no status destas, que podem manifestar suas opiniões e preocupações no procedimento, realizar atos processuais a portas fechadas em seu interesse e testemunhar através de declarações gravadas em vídeo ou áudio, entre outras disposições previstas nos artigos 68 e 69 do Estatuto. No entanto, as iniciativas com objetivo de resguardar vítimas e testemunhas dependem largamente da manifestação da vontade de cooperar do Estado envolvido com o crime sob a competência do Tribunal. A mesma situação ocorre com o artigo 70 do Estatuto, que trata dos crimes cometidos contra a administração da justiça pelo Tribunal Penal Internacional. As condutas criminosas previstas no Estatuto de Roma geralmente estão relacionadas a ações ou omissões dos Estados e os atos de não cooperação enfrentados pelos Tribunais da Ex-Iugoslávia e de Ruanda originaram-se de autoridades estatais. Mesmo assim, nos termos do art. 70, (4), “a”, caberá ao Estado envolvido processar os crimes contra a administração da justiça, tornando extensiva suas normas penais de direito, a partir de uma solicitação do Tribunal Penal Internacional. ${ }^{66}$

Torna-se, claro, portanto que o modelo de cooperação do Tribunal Penal Internacional atende principalmente aos interesses dos Estados, concedendo-lhes salvaguardas e, principalmente, limitando às possibilidades de ação do Tribunal em face da não cooperação por parte dos Estados. Nesse sentido, Antônio Cassese afirma que:

The Statute could have specified that the Assembly of States Parties might agree upon countermeasures, or authorize contracting states to adopt such countermeasures, or, in the event of disagreement, that each contracting state might take such countermeasures. In addition, it would have been appropriate to provide for the possibility of the Security Council stepping in adopting sanctions even in cases where the matter had not been previously referred by this body to the Court: one fails to see why the Security Council should not act upon Chapter VII if a state refuses to cooperate

${ }^{66}$ OOSTERVELD, Valerie; PERRY, Mike; McManus, John. The Cooperation of States with the International Criminal Court. Fordham International Law Journal, [S. 1.] v. 25, n. 3, p. 767-839, Mar. 2002. 
and such refusal amounts to threat the peace, even in cases previously referred to the Court by a state or initiated by the Prosecutor "proprio motu". Of course, this possibility is not excluded by the ICC Statute, but it also would have been a good idea expressly to include it. ${ }^{67}$

Assim, mesmo em um regime de cooperação "horizontal”, o Estatuto poderia dispor de forma mais específica a respeito das alternativas do Tribunal em caso de não cooperação. Tal alternativa, por sua vez, seria concernente com a Teoria da Responsabilidade Internacional do Estado por Atos Ilícitos, como será visto abaixo.

\section{0 modelo de cooperação do tribunal penal internacional à luz da teoria da responsabilidade internacional do estado por atos ilícitos}

A teoria da responsabilidade internacional é fruto de um processo de codificação das normas jurídicas internacionais, sendo, provavelmente, o último grande projeto nesse sentido. ${ }^{68}$ A noção de que um Estado pode ser responsabilizado internacionalmente vem do próprio princípio "pacta sunt servanda”: o Estado deve manter os compromissos que assumiu e, em caso de dano por seu descumprimento, buscar a reparar o prejuízo que causou. Entretanto, somente a partir da proposição da existência de uma ordem jurídica internacional que se pode entender a ideia

${ }^{67}$ CASSESE, Antonio. The Statute of the International Criminal Court: some preliminary reflections. European Journal of International Law, Oxford, v. 10, n. 1, p. 144-171, May 1999. "O Estatuto deveria ter especificado que a Assembléia dos Estados Parte deve concordar com as contramedidas, ou autorizar Estados envolvidos a adotar tais contramedidas, ou, em caso de desacordo, que cada Estado envolvido deve tomar tais contramedidas. Além disso, seria apropriado prever a possibilidade do Conselho de Segurança adotar sanções até mesmo em casos onde o assunto tenha sido previamente levado ao Tribunal pelo Conselho: não é possível entender porque o Conselho de Segurança não deve agir sob o Capítulo VII se um Estado se recusa a cooperar e tal recusa constituir uma ameaça a paz, mesmo em casos previamente denunciados ao Tribunal por um Estado ou iniciados pelo Procurador a "próprio motu". Certamente, essa possibilidade não é excluída pelo Estatuto do Tribunal Penal Internacional, mas teria sido uma boa ideia inclui-la expressamente. (tradução nossa)”

${ }^{68}$ CARON, David D. The ILC Articles on State responsibility: the paradoxical relationship between form and authority. The American Journal of International Law, [S. 1.] v. 36, n. 4, p. 857-873, Out. 2002. 
que, existindo lesão a direitos ou interesses de um Sujeito de Direito Internacional em relação a outro, em virtude de descumprimento de obrigação entre eles assumida, possa existir a previsão de um mecanismo jurídico de responsabilização ${ }^{69} \mathrm{~A}$ partir desse mecanismo de responsabilização é que o Estado pode ser entendido como responsável internacionalmente por todo ato ou omissão que viole norma internacional e que lhe seja atribuível.

O referencial teórico da teoria da responsabilidade internacional é dado pelo Projeto da Convenção sobre Responsabilidade dos Estados por Atos Ilícitos, elaborado pela Comissão de Direito Internacional, entidade que tem como missão codificar e desenvolver o Direito Internacional - principalmente através da positivação do costume - nos termos do artigo 13, (1), a, da Carta da ONU. ${ }^{70}$ A Assembleia Geral da ONU lhe conferiu mandato nesse sentido, através da Resolução n. 174 (II) de 1947, tendo a Comissão atuado em matérias como o Direito dos Tratados e a regulamentação das relações diplomáticas e consulares, entre outras. ${ }^{71}$

O texto sobre responsabilidade estatal por atos ilícitos internacionais apresenta o formato de um tratado, com cinquenta e nove artigos e comentários interpretativos ao final, embora a Assembleia Geral da ONU tenha decidido não convocar uma Conferência de Plenipotenciários para apreciá-lo, de acordo com a recomendação da própria Comissão. ${ }^{72} \mathrm{~A}$ justificativa dada para essa recomendação é que uma Conferência é um processo trabalhoso e imprevisível que pode resultar em emendas prejudiciais a um texto elaborado coletivamente durante quarenta

${ }^{69}$ DIHN, Nguyen Quoc; DAILLIER, Patrick; PELLET, Alain. Direito internacional público. 2. ed. Lisboa: Fundação Calouste Gulbenkian, 2003.

${ }^{70}$ NACOES UNIDAS.Decreto-Lei n. 7935/1945 (Carta das Nações Unidas). Artigo 13. 1. Disponível em: <www.planalto.gov.br>. Acesso em 13 abr. 2010. A Assembleia Geral iniciará estudos e fará recomendações, destinados a: a) promover cooperação internacional no terreno político e incentivar o desenvolvimento progressivo do direito internacional e sua codificação [...]

${ }^{71}$ CARON, David D. The ILC Articles on State responsibility: the paradoxical relationship between form and authority. The American Journal of International Law, [S. 1.] v. 36, n. 4, p. 857-873, Oct. 2002.

72 CARON, David D. The ILC Articles on State responsibility: the paradoxical relationship between form and authority. The American Journal of International Law, [S. 1.] v. 36, n. 4, p. 857-873, Oct. 2002. 
anos, além do fato de que eventuais reservas legitimariam posturas não cooperativas por parte dos Estados. ${ }^{73}$ Isso poderia significar uma menor influência para o Projeto da Comissão do que ele tem agora, pois suas disposições não só são adotadas como se fosse Lei pelas cortes arbitrais internacionais como pela própria Corte Internacional de Justiça. ${ }^{74}$ Atuando em um vácuo normativo, o texto da Comissão de Direito Internacional torna-se mais influente do que um tratado multilateral. ${ }^{75}$

Dentro da estrutura da obrigação jurídica internacional, o mecanismo da responsabilização estatal por atos ilícitos depende, obviamente, da noção de ato ilícito internacional. $\mathrm{O}$ artigo $2^{\circ}$ do Projeto da Convenção dispõe que existe fato internacionalmente ilícito quando uma ação ou omissão atribuível a um Estado constitui violação de uma obrigação internacional. ${ }^{76} \mathrm{~A}$ doutrina clássica exigia a ocorrência de um dano para a configuração da responsabilidade, mas o entendimento da Comissão evoluiu para a ideia de que a ocorrência do fato internacionalmente ilícito "é condição necessária e suficiente para o comprometimento da responsabilidade". O Projeto da Convenção estabelece, em seu artigo $3^{\circ}$, que o conceito de ato ilícito é uma noção autônoma de Direito Internacional, ou seja, o ato que o Direito interno do Estado reputa como lícito pode ser ilícito perante o Direito Internacional. ${ }^{77}$ Como consequência, normas jurídicas internas (leis, decretos) e decisões administrativas serão consideradas como fato e poderão ser veículo de um ato ilícito internacional. ${ }^{78}$

${ }^{73}$ CARON, David D. The ILC Articles on State responsibility: the paradoxical relationship between form and authority. The American Journal of International Law, [S. 1.] v. 36, n. 4, p. 857-873, Oct. 2002.

${ }^{74}$ MILANOVIC, Marko. State responsibility for genocide: a follow up. European Journal of International Law, Florence v. 18, n. 4, p. 669-694, Oct. 2007.

${ }^{75}$ CARON, David D. The ILC Articles on State responsibility: the paradoxical relationship between form and authority. The American Journal of International Law, [S. 1.] v. 36, n. 4, p. 857-873, Oct. 2002.

${ }^{76}$ INTERNATIONAL LAW COMMISSION. Responsibility of States for internationally wrongful acts. Disponível em: <www.un.org/law/ilc/>. Acesso em: 10 jun. 2008.

${ }^{77}$ INTERNATIONAL LAW COMMISSION. Responsibility of States for internationally wrongful acts. Disponível em: <www.un.org/law/ilc/>. Acesso em: 10 jun. 2008.

${ }^{78}$ DIHN, Nguyen Quoc; DAILLIER, Patrick; PELLET, Alain. Direito internacional público. 2. ed. Lisboa: Fundação Calouste Gulbenkian, 2003. 
Coube ao terceiro relator do Projeto da Convenção, Roberto Ago, a introdução no tema da responsabilidade internacional da distinção entre obrigação primária e obrigação secundária a partir da qual o cometimento de um ato ilícito ou a violação de uma obrigação internacional (primária) faz nascer uma ou várias obrigações secundárias como a cessação do ato ilícito, a satisfação moral através de um pedido de desculpas ou a indenização. ${ }^{79}$ Assim, do mecanismo da responsabilidade resulta uma nova relação jurídica entre o Estado autor do ato ilícito ou descumprimento e o Sujeito de Direito Internacional. ${ }^{80}$ É possível, assim, uma coerência dentro da matéria e, consequentemente, a afirmação da responsabilidade internacional como um princípio geral do Direito Internacional. ${ }^{81} \mathrm{~A}$ distinção formal entre obrigação primária e secundária também enseja a criação de procedimentos internacionais para determinação de responsabilidade que concorrem para a proporcionalidade das contramedidas. ${ }^{82}$

Embora originalmente concebido para as relações entre Estados (a primeira versão do Projeto data dos anos cinqüenta), é possível invocarem-se os artigos nas obrigações surgidas entre Estados e organizações internacionais, porque ambos são Sujeitos de Direito Internacional e, portanto, aptos a assumirem direitos e obrigações. ${ }^{83}$ À luz da Teoria da Responsabilidade Internacional, percebe-se claramente que o descumprimento de um Estado de sua obrigação de cooperar com o Tribunal Penal Internacional corresponderia a um ato ilícito passível de res-

${ }^{79}$ CRAWFORD, James. The ILC's Articles on Responsibility of States for International Wrongful Acts: A Retrospect. American Journal of International Law, [S. 1.] Washington D.C., v. 96, n. 41, p. 874-890, Set. 2002.

${ }^{80}$ DIHN, Nguyen Quoc; DAILLIER, Patrick; PELLET, Alain. Direito internacional público. 2. ed. Lisboa: Fundação Calouste Gulbenkian, 2003.

${ }^{81}$ MILANOVIC, Marko. State responsibility for genocide. European Journal of International Law, Florence, v. 17, n. 3, p. 553-604, Mar. 2006.

82 BEDERMAN, David J. Counterintuiting countermeasures. The American Journal of International Law, Washington D.C., v. 96, n. 4. p. 817-832, oct. 2002.

${ }^{83}$ CRAWFORD, James. The ILC's Articles on Responsibility of States for International Wrongful Acts: A Retrospect. American Journal of International Law, Washington D.C., v. 96, n. 41, p. 874-890, Set. 2002. O último relator do Projeto da Convenção sobre Responsabilidade Estatal por Atos Ilícitos, James Crawford, reconheceu o envelhecimento do texto em relação ao Direito Internacional contemporâneo, afirmando que os artigos refletem uma ultrapassada aproximação estatalista da matéria, baseada primordialmente nas relações bilaterais entre Estados. 
ponsabilizá-lo internacionalmente. Nesse sentido, segue o entendimento da Corte Internacional de Justiça em recente julgado no qual condenou a República da Sérvia e Montenegro por não colaborar com o Tribunal Penal Internacional para a Ex-Iugoslávia na repressão aos atos de genocídio e aos crimes contra a humanidade ocorridos no território da Ex-Iugoslávia, durante a década de $1990 .{ }^{84}$ Portanto, seria possível juridicamente que o Tribunal Penal Internacional dispusesse em seu Capítulo IX sobre a obrigação do Estado em cooperar com o Tribunal Penal Internacional, prevendo sanções diretas (contramedidas) ao Estado que indevidamente deixe de cooperar com o Tribunal Penal Internacional.

\section{Conclusão}

Buscou-se, neste artigo, demonstrar que o modelo de cooperação estabelecido no Estatuto de Roma é grandemente orientado aos interesses dos Estados a cuja cooperação será dirigido. ${ }^{85}$ Em comparação aos Tribunais "Ad Hoc" da ex-Iugoslávia e de Ruanda, o modelo de cooperação do Tribunal Penal Internacional possui menos recursos que os de seus predecessores (que enfrentaram grandes problemas nessa área) e, desse modo, constitui-se no calcanhar de Aquiles da instituição. ${ }^{86}$ Não é surpreendente, assim, o fato de que, em seus primeiros anos de atuação, o Tribunal tenha encontrado dificuldades em cumprir seu mandato e esteja envolvido em impasses diplomáticos.

Sendo o Tribunal Penal Internacional uma corte cuja legitimidade é calcada não apenas nos valores que garante, mas no fato de ser a expressão da vontade da comunidade internacional é, em certa medida, natural que seu modelo de coope-

\footnotetext{
${ }^{84}$ Neste sentido, vide: MILANOVIC, Marko. State responsibility for genocide. European Journal of International Law, Florence, v. 17, n. 3, p. 553-604, Mar. 2006.

${ }^{85}$ CASSESE, Antonio. The Statute of the International Criminal Court: some preliminary reflections. European Journal of International Law, Florence, v. 10, n.3, p. 144-171, May 1999.

${ }^{86} \mathrm{ZHOU}, \mathrm{Han}-\mathrm{Ru}$. The enforcement of arrest warrants by the International Forces: from the ICTY to the ICC. Journal of International Criminal Justice, Oxford, v. 4, p. 202-218, Nov. 2005 .
} 
ração seja mais restrito do que aquele imposto pelo Conselho de Segurança em seus tribunais "ad hoc". Não se deve olvidar, contudo, que o compromisso com a efetividade seja inerente ao mandato de qualquer jurisdição, doméstico ou internacional. $\mathrm{O}$ atual modelo de cooperação é prejudicial ao Tribunal, porque adotou como pressuposto os princípios e normas de cooperação judicial entre Estados, a chamada "cooperação horizontal". Esse modelo, contudo, traz limitações muito claras no plano das relações entre o Tribunal e os Estados requeridos. Incapaz de barganhar o ato de cooperação, oferecendo, por exemplo, a reciprocidade de tratamento, como ocorre com os tratados bilaterais de extradição, o Tribunal oferece poucas vantagens concretas ao Estado a que se pede cooperação, tampouco um aparelho de segurança capaz de ameaçar qualquer retaliação. Por outro lado, o ato requerido, geralmente, traz um preço político claro, dado pelo descontentamento de outros Estados ou, muitas vezes, pelo descontentamento de sua própria sociedade.

Deve-se ter em mente que o modelo de cooperação do Tribunal Penal Internacional é um primeiro passo dado sob um novo fundamento de legitimidade, e que, portanto, o caráter evolutivo de suas normas é inegável. ${ }^{87}$ Dessa forma, faz-se necessária a implementação de novas regras de cooperação que garantam a efetividade da jurisdição complementar do Tribunal Penal Internacional. A ênfase no desenvolvimento do modelo de cooperação do Tribunal deve concentrar-se no estudo de mecanismos de imposição que ajudem a superar o pragmatismo das políticas externas estatais. Sem esses mecanismos, o Tribunal Penal Internacional corre o risco de falhar em seus propósitos, postergando assim sua parcela de contribuição para a realização do ideal de paz e justiça dentro da comunidade internacional.

${ }^{87}$ BUCHET, Antoine. Le transfert devant les juridictions internationals. In: ASCENSIO, Hervé; DECAUX, Emmanuel; PELLET, Alain (Org.) Droit international penal. Paris: A. Pedone, 2000. p. 969-980. 


\section{The cooperation model of the international criminal court}

\section{Abstract}

This article studies the cooperation model of the Rome Statute seeking to determine why the International Criminal Court have faced problems in this area. It is believed that a systematic analysis of the topic to the Theory of International State Responsibility for Wrongful Acts can contribute significantly to dealing with such issues. For that, this work performs an analysis of the articles of Chapter IX of the document, by means of the deductive method, to show its shortcomings and contradictions. It concludes that the current model of cooperation present in the Rome Statute does not allow the International Criminal Court faithfully fulfill their duties because it preserves state prerogatives in too much and does not provide specific sanctions for non compliance with the requests for cooperation addressed to States.

Keywords: International Criminal Court. Rome statute. International cooperation.

\section{Referências}

AKHAVAN, Payam. Are International Criminal Tribunals a disincentive to peace?: Reconciling judicial romantism with political realism. Human Rights Quarterly, Cincinnati, n. 31, p. 624-654, 2009.

ARBOUR, Louise. The international tribunals for serious violations of international humanitarian law in the former Yugoslavia and Rwanda. McGill Law Journal, Montreal, n. 46, p. 195-201, 2000.

BEDERMAN, David J. Counterintuiting countermeasures. The American Journal of International Law, Washington D.C., v. 96, n. 4. p. 817-832, Oct. 2002.

BRASIL. Decreto-Lei n. 7935 de 04 de setembro de 1945. Aprova a Carta das Nações Unidas. Disponível em: <www.planalto.gov.br>. Acesso em: 15 abr. 2010.

BRASIL. Decreto n. 56.435 de 08 de junho de 1965. Promulga a Convenção de Viena sobre relações diplomáticas e consulares. Disponível em: <www.planalto.gov.br >. Acesso em 15 abr. 2010. 
BRASIL. Decreto n. 4.388 de 25 de setembro de 2002. Promulga o Estatuto de Roma do Tribunal Penal Internacional. Disponível em: <www.planalto.gov.br>. Acesso em: 13 abr. 2010.

BUCHET, Antoine. Le transfert devant les juridictions internationals. In: ASCENSIO, Hervé; DECAUX, Emmanuel; PELLET, Alain (Org.) Droit international penal. Paris: A. Pedone, 2000. p. 969-980.

CASSESE, Antonio. The Statute of the International Criminal Court: some preliminary reflections. European Journal of International Law, Oxford, v. 10, n.1, p. 144-171, May 1999.

CARON, David D. The ILC Articles on State responsibility: the paradoxical relationship between form and authority. The American Journal of International Law, [S. 1.] v. 36, n. 4, p.857-873, Oct. 2002.

CIAMPI, Annalisa. Sull'applicazione della teoria dei poteri impliciti da parte del Tribunale Penale Internazionale per la ex-Iugoslavia. Rivista di Diritto Internazionale, Milano, v. 81, n. 1, p.130-146, jun. 1998.

CRAWFORD, James. The ILC's Articles on Responsibility of States for International Wrongful Acts: A Retrospect. American Journal of International Law, Washington D.C., v. 96 , n. 41 , p. $874-890$, set. 2002.

DIHN, Nguyen Quoc; DAILLIER, Patrick; PELLET, Alain. Direito internacional público. 2. ed. Lisboa: Fundação Calouste Gulbenkian, 2003.

HIZUME, Gabriella de Camargo. Breves reflexões acerca da questão da cooperação jurídica no Tribunal Penal Internacional. In: MENEZES, Wagner (Coord.). Estudos de direito internacional: anais do $5^{\circ}$ Congresso Brasileiro de Direito Internacional. Curitiba: Juruá, 2007. p. 187-193. v. 5.

INTERNATIONAL CRIMINAL COURT. Assembly of the States Parties. Report of the bureau of stocktaking: cooperation, New York, p. 22-25 mar. 2010. Session 8.

INTERNATIONAL CRIMINAL COURT. Assembly of States Parties. Rules of procedure and evidence. Disponível em: <www.icc-cpi.int>. Acesso em: 30 abr. 2010.

INTERNATIONAL CRIMINAL COURT. Office of the Registrar. Ratification Status. Disponível em: <www.icc-cpi.int>. Acesso em: 30 abr. 2010. 
INTERNATIONAL LAW COMMISSION. Responsibility of States for internationally wrongful acts. Disponível em: < www.un.org/law/ilc/>. Acesso em: 10 jun. 2008.

KING, Faiza Patel; LA ROSA, Anne Marie. Jurisprudence of the International Criminal Tribunal for the Former Yugoslavia. European Journal of International Law, [S. 1.] v. 9, p. 756-760, Nov. 1998.

KREB, Claus. Penas, execução e cooperação no estatuto para o Tribunal Penal Internacional. In: HOUKR, Fauzi Hassan; AMBOS, Kai. Tribunal penal internacional. São Paulo: Revista dos Tribunais, 2000. p. 125-147.

MILANOVIC, Marko. State responsibility for genocide. European Journal of International Law, Florence, v. 17, n. 3, p. 553-604, mar. 2006.

MILANOVIC, Marko. State responsibility for genocide: a follow up. European Journal of International Law, Florence v. 18, n. 4, p. 669-694, Oct. 2007.

MIRANDA, Jorge. A incorporação ao direito interno de instrumentos jurídicos de direito internacional humanitário e direito internacional dos direitos humanos. Revista CEJ, n. 11, p. 23-26, maio Ago. 2000.

NSEREKO, Daniel N. Genocidal conflict in Rwanda and the ICTR. Netherlands International Law Review, Hague, v. 48, n.1, p.31-65, Mar. 2001.

OOSTERVELD, Valerie; PERRY, Mike; McManus, John. The Cooperation of States with the International Criminal Court. Fordham International Law Journal, v. 25, n. 3, p. 767-839, Mar. 2002.

PAULUS, Andreas L. The legalist groundwork of the International Criminal Court: commentaries on the Statute of the International Criminal Court. The European Journal of International Law, [S. 1.] v. 14, n. 4, p. 843-860, Dec. 2003.

PERRONE-MOISÉS, Cláudia. O princípio da complementaridade no Estatuto do Tribunal Penal Internacional e a soberania contemporânea. Revista Política Externa, [S. 1.] v. 8, n. 4, p. 3-11, mar./maio 2000.

PESKIN, Victor. Caution and confrontation in the International Criminal Court's pursuit of accountability in Uganda and Sudan. Human Rights Quarterly, Cincinnati, v. 31, n. 3, p. 655-691, Aug. 2009. 
UBÉDA, Muriel. L'Obligation de coopérer avec les juridictions internationales. In: ASCENSIO, Hervé, DECAUX, Emmanuel; PELLET Alain (Org.) Droit international penal. Paris: A. Pedone, 2000. p. 951-967.

YUGOSLAVIA. International Criminal Tribunal. Statute of the International Tribunal for the prosecution of persons responsible for Serious Violations of International Humanitarian Law committed in the Territory of the Former Yugoslavia since 1991, U.N. Doc. S/25704 at 36, annex (1993) and S/25704/Add.1 (1993), adopted by Security Council on 25 May 1993, UN. Doc. S/RES/827 (1993). Yugoslavia, 25 may 1993. Disponível em: <http://www1.umn.edu/humanrts/icty/ statute.html>. Acesso em: 17 nov. 2010

ZAPALLÀ, Salvatore. The reaction of the US to the entry into Force of the ICC Statute: comments on UN SC Resolution 1422 (2002) and article 98 agreements. Journal of International Criminal Justice, Florence, v. 13, n. 1, p. 114-134, Jan. 2002.

ZHOU, Han-Ru. The enforcement of arrest warrants by the International Forces: from the ICTY to the ICC. Journal of International Criminal Justice, Oxford, v. 4, n. 2, p. 202-218, Nov. 2005. 
